\title{
De bosques, sueños, galaxias y mares: poemas y narrativas para niños y adolescentes
}

\author{
Of Forests, Dreams, Galaxies, and Seas: Poems and Narratives for \\ Children and Adolescents
}

\author{
De boscos, somnis, galàxies i mars: poemes i narratives per a \\ infants $i$ adolescents
}

\author{
Amarilis Hidalgo de Jesús. Bloomsburg University of Pennsylvania. \\ ahidalgo@bloomu.edu \\ https://orcid.org/0000-0001-5437-6271
}

\begin{abstract}
Extended abstract
To talk about children's and youth's literature in Latin America is to talk about the history of oppression, geography, fauna, multiple languages, and culture of the Latin American nations. Latin American cultural borders, with distinctive geographical spaces, have provided cultural conditions for the creation of a unique regional children's and youth's literature permeated by the linguistic and historical richness of the Latin American nations; which, even, has gone as far as the creation of sidereal spaces in which children can dream. Latin America cannot and should not be seen as a homogeneous conglomerate of nations, because the linguistic and cultural diversity of the countries that comprise it goes far beyond the generalized idea of political turmoil created and supported by imperialistic nations. These heterogeneous nations have created a universal children's literature that it is rooted in Latin American regional cultures. Therefore, it is not surprising that a series of themes stand out in Latin American children's literature, which not only adhere to different regional aspects, but are also composed by thematic elements which are part of world children's and youth's literature. All these themes are as well a fundamental part of the development of children's literature in the Americas.
\end{abstract}

In the poems and stories studied in this essay, the themes revolve around images of Latin American fauna and flora and intergalactic imaginary travels. Likewise, the themes are interrelated with contemporary topics, such as sexuality, marginalization, destruction of the environment and personal harassment; topics not too often very covered in Latin American children's literature. In the essay I am examining the children's literature of Latin America within the perspective of gender, cultural values, and environment. The study is based on a thematic analysis of children's literature written by Bella Clara Ventura (Colombia / Mexico), Amarilis Hidalgo de Jesús (Puerto Rico), María Luisa Lazzaro (Venezuela), Ana María Guillén Lazzaro (Venezuela) and María Juliana Villanueva (Puerto Rico). The essay has been divided into two parts: "Flora and Fauna, Gender and Environment" and "The Fight for the Environment in an Intergalactic Journey." All themes are combined through images of animals, or journeys to other galaxies based on the recovery of the environment. In the first part, the stories and poems are analyzed within the context of animals whose voices are the major narrative voices in the story, thus creating an environmentalist and gender discourse through a progressive fauna discourse. In the second part, the environmental 
theme evolves around the voice of a girl, Aurora, and her travel to other planets in search of help to save Earth. Stories, poems and a short novel/long short story have been chosen as the basis of the study that, to a certain extent, symbolize the new path of Latin American children's writing within a spatial, narrative and thematic framework that breaks with the traditional patriarchal statutes of the children's literature in the literary history of Latin America. In the first part "Flora, Fauna, Gender and Environment" we analyze poems written by Bella Clara Ventura, a poem and short story written by Amarilis Hidalgo de Jesús, a poem written by María Luisa Lazzaro, and a story written by Ana María Guillen Lazzaro within a cultural, environmental and gender perspective. In the second part, "The fight for the Environment in an Intergalactic Journey", we analyze the short novel Aurora and her intergalactic travels by María Juliana Villafañe (Puerto Rico). Unlike the other texts studied, in this short novel/long short story the themes of gender, culture and environment are presented within an extrasensory and sidereal perspective seen through the eyes of a girl and her friendship with a prince from another galaxy.

In the texts studied, similar themes are explored within a universal cultural context through the lived experience of each of the characters, or poetic voices. Similarly, there is a literary and cultural connection in these texts that revolves around the development of an analogous Latin American theme with linguistic elements that, although different in each nation, are also part of the Latin American cultural conglomerate. Each text represents the cultural and social reality that Latin American nations live through political, gender, cultural, and religious conflicts. Without a doubt, this conglomeration of themes is important when approaching the study of the literary production of children's literature in Latin American societies, where fauna and human imagination echo the social, political and ecological problems that these nations have passed through. Therefore, when entering his study, a researcher necessarily has to know the history and idiosyncrasies of the Latin American people in order to understand the children's literary production of Latin American nations.

Keywords: Latin American children's literature, children's poetry, miscenegation

\section{Resumen}

Hablar de literatura infantil y juvenil en Latinoamérica es hablar de la historia del mestizaje, la geografía y la cultura de nuestras naciones. Las fronteras culturales latinoamericanas, con distintivos rasgos geográficos, han dado pie a la creación de una literatura para niños y una literatura juvenil permeada por la riqueza lingüística e histórica de nuestras naciones; la que, inclusive, ha llegado hasta la creación de espacios siderales en los cuales los niños puedan soñar. Latinoamérica no puede ni debe ser vista como un conglomerado homogéneo de naciones, puesto que la diversidad lingüística y cultural de los países que la conforman va mucho más allá de la idea generalizadora que se ha creado de estas naciones. Todo este conjunto de naciones heterogéneas ha creado una literatura infantil que, si bien se ha arraigado en las culturas regionales latinoamericanas, también se ha universalizado. Por ende, no es de extrañar que en la literatura infantil se destaquen una serie de temas, que no solo se adhieren a distintos aspectos regionales, sino que asimismo se mezclan con elementos temáticos que son también parte de literaturas infantiles y juveniles mundiales. Todos estos temas son parte fundamental de los poemas y cuentos que se estudian en este trabajo, cuyas temáticas giran en torno a las imágenes de la fauna y la flora latinoamericana y viajes intergalácticos. Asimismo, los temas se interrelacionan con tópicos contemporáneos, como la sexualidad, la marginación, la destrucción del ambiente y el acoso personal; temas no muy tratados en la literatura para niños latinoamericana.

Palabras clave: Literatura infantil hispanoamericana, poesía infantil, mestizaje 
Resum

Parlar de literatura infantil i juvenil a Llatinoamèrica és parlar de la història del mestissatge, la geografia i la cultura de les nostres nacions. Les fronteres culturals llatinoamericanes, amb distintius trets geogràfics, han donat peu a la creació d'una literatura per a infants i una literatura juvenil amerada de la riquesa lingüística i històrica de les nostres nacions, la qual, fins i tot, ha arribat fins la creació d'espais siderals en els quals els infants puguen somniar. Llatinoamèrica no pot, ni ha de ser vista, com un conglomerat homogeni de nacions, atés que la diversitat lingüística i cultural dels països que la conformen, van molt més enllà de la idea generalitzadora que s'ha creat d'aquestes nacions. Tot aquest conjunt de nacions heterogènies ha creat una literatura infantil que, si bé ha arrelat en les cultures regionals llatinoamericanes, també s'ha universalitzat. En conseqüència, no és estrany que a la literatura infantil es destaquen una sèrie de temes que no sols s'adhereixen a distints aspectes regionals, sinó que també es barregen amb elements temàtics que són també part de literatures infantils i juvenils mundials. Tots aquests temes són part fonamental dels poemes i contes que s'estudien en aquest treball, les temàtiques dels quals giren entorn a les imatges de la fauna i la flora llatinoamericanes i viatges intergalàctics. Així mateix, els temes s'interrelacionen amb tòpics contemporanis com la sexualitat, la marginació, la destrucció de l'ambient i l'assetjament, temes no molt tractats en la literatura per a infants llatinoamericans.

Paraules clau: Literatura infantil i juvenil llatinoamericana, poesia infantil, mestissatge.

\section{Introducción}

La literatura infantil latinoamericana se caracteriza por el uso de imágenes que aluden a la fauna, la flora y su geografía. Cada imagen a su vez se conecta con las distintas culturas que se han desarrollado en el continente americano. Por tanto, no es de extrañar que cada nación latinoamericana se acerque a su literatura infantil de una manera muy peculiar y escueta, a la vez que la integra a ese arcoíris cultural y lingüístico que arropa al continente americano. Un arcoíris desintegrado en mares, ríos, montañas y animales coloridos que se entremezclan con la historia y la cultura de cada nación latinoamericana y el asedio cultural, económico y de su vecino del norte. Teniendo en consideración lo anterior, en este ensayo propongo hacer un estudio temático de la literatura infantil escrita por Bella Clara Ventura (Colombia/México), Amarilis Hidalgo de Jesús (Puerto Rico), María Luisa Lazzaro (Venezuela), Ana María Guillén Lazzaro (Venezuela) y María Juliana Villanueva (Puerto Rico). El ensayo se ha dividido en dos partes: Flora y fauna, género y medio ambiente y La lucha por el ambiente en un viaje intergaláctico. Ambos temas se compaginan mediante imágenes de animales o viajes a otras galaxias basados en la recuperación del medioambiente. En la primera parte, se analizan cuentos y poemas en los cuales se le da voz a los animales, creándose así un discurso ambientalista y de 
género a través de un discurso de fauna progresista. En la segunda parte, se vuelve a retomar el tema ambientalista en la voz de una niña, Aurora, y su viaje a otros planetas en busca de ayuda para salvar a la Tierra. Se han escogido como base de estudio cuentos, poemas y una novela corta que, en cierta medida, simbolizan el nuevo camino de la escritura infantil latinoamericana dentro de un marco espacial, narrativo y temático que rompe con los estatutos patriarcales tradicionales de dicha literatura en la historia literaria de América Latina.

\section{Flora, fauna, género y medio ambiente}

En esta parte analizamos poemas de Bella Clara Ventura, un poema y un cuento de Amarilis Hidalgo de Jesús, un poema de María Luisa Lazzaro y un cuento Ana María Guillen Lazzaro dentro de un ámbito cultural, medioambiental y de género.

\subsection{Bella Clara Ventura, Hechizos de Bosque (Colombia/México)}

La idea del multiculturalismo ha sido conectada a las injusticias sociales y su habilidad de reconocer diferencias culturales y raciales, normas sociales y perspectivas personales mientras

En estos poemas la voz poética alaba el poder de la naturaleza y la fauna a través del cántico de aves, mamíferos, peces, animales mitológicos y sirenas dentro de un marco de hechizos; los que levantan la voz por medio de personificaciones y cantos melodiosos, que recuerdan muchas veces, versos bíblicos, fábulas o historias mitológicas que hemos oído desde niños se representan realidades sociales, políticas y económicas (Lalas, 2007). La judía colombo-mexicana, como se autodenomina Bella Clara Ventura, no ajena a esto en su libro de poemas Hechizos de Bosque recoge una serie de imágenes de animales universales $\mathrm{y}$ regionales a los que da voz a través de los versos de su poesía. En estos poemas la voz poética alaba el poder de la naturaleza y la fauna a través del cántico de aves, mamíferos, peces, animales mitológicos y sirenas dentro de un marco de hechizos; los que levantan la voz por medio de personificaciones y cantos melodiosos, que recuerdan muchas veces, versos bíblicos, fábulas o historias mitológicas que hemos oído desde niños. Cada poema está acompañado de un simple dibujo del animal o personaje en blanco y negro. La voz poética tiende a ser exclamativa y precisa al describir la función de cada ente dentro del reino animal y se entremezcla en muchos de los poemas con voces de la mitología griega, como por ejemplo en "Caballito de Mar" en donde se conecta al personaje con la mitología europea, "Erguido, rey de historia. Mitología entre burbujas de luz" (p. 12) o en "El camello" en donde se describe, paso a paso, la constitución del animal, su piel y su función dentro del transporte en el desierto, a la vez que se relaciona con la 
temática árabe a través de la mención de un personaje de sus cuentos, "Al compás de Alí Baba, su sombra usurpadora de sueños" (p. 13).

Muchas veces en esta colección de poemas de adolescentes, el lenguaje poético es parco y accesible a la imaginación de aquellos; otras veces se vuelve duro y hasta un poco grotesco para distintos tipos de sensibilidad humana; lo que se puede ver en el poema "Las palomas" mediante el uso de un lenguaje grotesco y disonante, en el que se utilizan palabras denominadas "malas" o fuertes para el lenguaje de una persona cuyo público es adolecente, "la cabeza del héroe adornada de excrementos, recuerda que aún en la eternidad la mierda nos cae a todos por igual" (p. 44). Por otra parte, en el poema "El pato" el lenguaje toma un tono más erudito y complicado para un niño, a la vez que se refleja en la temática de un cuento clásico transformado en un símbolo de libertad humana. De igual modo, la voz poética oscila entre el uso de un lenguaje simple y complicado, en el cual la historia del patito feo se transforma en la ruptura con el miedo a la libertad. Una ruptura en la que la imagen de la luna convertida en espejo y su relación con los cantos de eunucos, seres mutilados sexualmente por el poder masculino, combinados con las imágenes de "bajo una noche luminosa" se rebelan para ir en busca de un camino perdido, ya bien sexual, social o racial representado en el patito feo convertido en cisne o el eunuco, "Una noche luminosa y de cantos de eunuco, la luna se convirtió en espejo" (p. 41). Pero por un momento, no sabemos a cuál de los tres mundos terminará uniéndose la voz poética, si al del cisne bello, "El patito feo comprobó cómo sus plumas cambiaban de volumen. Despejando miedos y dolores. En cisne se transformó" (p. 41) o al de las imágenes del canto de los eunucos, que dentro de su mutilada sexualidad se han transformado en cantos de voces suaves y melódicas, "Sonriente, volvió a la laguna donde lanzó su último lamento" (p. 41). Así pues, su transformación de patito feo a cantos de eunuco y finalmente a cisne, visto a través de su imagen en el espejo de la luna, le hace ver que no es distinto sino diverso, por lo cual, al romper con su último lamento, rompe con el mito de la fealdad y se convierte en el portavoz de una libertad racial, social y de género.

Botelho \& Rudman han expresado que existe una dualidad en la representación de discursos culturales e históricos en la literatura de niños (Botehlo \& Rudman, 2009, p. 104). Por ello es importante hacer hincapié, según Malcolm \& Lowery (2011), en la representación de los temas de raza y clase (Malcolm\& Lowery, 2011, p. 44). En Hechizos de Bosque, asimismo hay poemas en los que los estereotipos se revierten para así validar un discurso racial y de género, en donde la voz poética se apodera de una voz femenina para darle fuerza al mensaje de rebeldía que se encarna en el comportamiento rebelde de una oveja negra, "escudriña a sus hermanas, Blancas y dóciles siguen al pastor. La oveja negra acorta el paso. Siente y huele diferente. No obedece" 
(p. 39). En el poemario también se alude al tema de la ruptura humana con el papel tradicional de la mujer dentro de la sociedad patriarcal. Un ejemplo de esto lo tenemos en "Las sirenas" en cuyas estrofas el canto a la idea tradicional de la libertad femenina emerge al principio del verso, "A veces nos olvidamos de ser mujeres" (p. 47) y "Ariscas nos asumimos como sirenas" (p. 47), el cual se va deconstruyendo a medida que avanza el poema y cuya libertad se rescata de ese laberinto de opresión social al cual se expone la mujer, "El cuerpo se cierra. Los sentimientos se desdibujan de la entrega. Nos enjoyamos de escamas" (p. 47). De este modo, el tema del poder de la mujer de controlar su cuerpo se vuelve a retomar en "La serpiente" en donde

La voz poética, asimismo, hace hincapié en que el animal ha sido castigado por su atrevimiento $y$, a diferencia de los otros poemas, lo que empieza como un signo progresista femenino, termina enredado en el discurso tradicional de opresión femenina religioso con el cual ha ido jugando la voz poética, "Rastrera, transgredió vedas. Tentó al hombre con el afán de igualdad" la poeta transforma la historia bíblica de Adán y Eva al convertir a la serpiente en ave, "Algún día pájaro fue" (p. 46) y al enfrentarla a Dios la hace portadora de un discurso de rebeldía del cual emerge una voz femenina. La voz poética, asimismo, hace hincapié en que el animal ha sido castigado por su atrevimiento y, a diferencia de los otros poemas, lo que empieza como un signo progresista femenino, termina enredado en el discurso tradicional de opresión femenina religioso con el cual ha ido jugando la voz poética, "Rastrera, transgredió vedas. Tentó al hombre con el afán de igualdad" (p. 46). En este poema primero se le da voz, libertad y poder a la serpiente para terminar contraponiéndolo al discurso tradicional bíblico anti-mujer. A esta temática de opresión femenina se añade el poema "Los cóndores" en el cual se presenta la visión tradicional bíblica de, "hasta que la muerte nos separe" (p. 22) mediante las imágenes del comportamiento de las parejas de cóndores ante el ciclo de vejez y muerte. De este modo, emergen discursos que, si bien son contradictorios, también rompen con los patrones de género establecidos para la mujer por siglos.

\subsection{Cuentos de Isla y Mar de Amarilis Hidalgo de Jesús (Puerto Rico)}

Las múltiples invenciones del "yo" en la poesía infantil tienen que ver con presentar el poema dentro de una visión de infancia, mediatizada por una voz poética adulta que se aproxima al modo de ver la vida de un niño (Bajour, n.d., p. 4). Los personajes de animales son la ruta perfecta para crear este entorno y relación entre un lector adulto y un receptor niño puesto que emisor o personaje es el que se encarga de transmitir la información con la que el lector u oyente niño se puede identificar, como se identificó Aydén, un niño de 5 años viviendo en Carolina del Sur, "Yo quiero ser como Are y Pita o como la olita, quiero regresar a Puerto Rico" (2018, febrero 
18). Y es dentro de este esquema poético de identificación que analizamos el poema "Are y Pita", ya que en este poema la relación receptor y emisor se complementa a través de la narración poética. Es decir, la historia de dos tortugas caribeñas se trasforma en un diálogo entre receptor y emisor que va más allá de una simple narración poética, puesto que las tortugas se convierten en un símbolo de resistencia ante los ojos de un pequeño espectador, que ya bien sea caribeño o de otra zona del planeta, se identifican con el mensaje de resistencia cultural y espacial que emerge detrás de la historia, "Are y Pita son dos tortuguitas que viven en un estanque en el centro de un país. A Are le gusta comer y a Pita dormir" (p. 9). Por tanto, la voz poética ha utilizado elementos de la cultura antillana que asocian a las tortugas con metáforas culturales que representan a la cultura musical del Caribe. Así, el elemento común que las une es el baile y la música que, a su vez, se convierten en

Por tanto, la voz poética ha utilizado elementos de la cultura antillana que asocian a las tortugas con metáforas culturales que representan a la cultura musical del Caribe. Así, el elemento común que las une es el baile y la música que, a su vez, se convierten en resistencia cultural ante la cultura anglosajona resistencia cultural ante la cultura anglosajona, "Are baila al son de la bachata y Pita nada cuando oye salsa" (p. 9). Por ende, el sueño de regresar, "a su ambiente natural" (p. 9) se convierte en la metáfora de liberación que va guiando al receptor, el niño, a utilizar su imaginación para ir visualizando el viaje del regreso, "Are y Pita son dos tortuguitas exploradoras de rutas buscando cómo llegar a una playa tropical, a la arena antillana, nido eterno del tinglar" (p. 9). Mediante este viaje de regreso, las tortugas se convierten en símbolos de fuerza y esperanza. Por lo tanto, para un niño de origen caribeño que vive en la zona

fría de los Estados Unidos, Are y Pita se tornan en modelos a seguir; y para un niño que no se identifica con esa cultura, Are y Pita son simplemente dos tortuguitas buscando su camino al mar. Es decir, como dice Ana Romero, "En la literatura infantil cuanto más cerca del lector estén los personajes más se identifica con la psicología de los personajes y más le gusta a un niño el libro que está leyendo" (Romero, 2012, p. 2).

Para crear literatura dirigida a niños se necesitan utilizar colores, espacios y personajes que atraigan la atención de un niño. Por eso es importante, los colores que se usen y el modo en que se configuran las ilustraciones que muchas veces muestran la manera en que se desarrolla la historia. En el caso del Caribe los colores en las ilustraciones son esenciales si la temática gira alrededor del mar, la tierra y la libertad. En Cuentos de Isla y Mar hay tres cuentos que se relacionan con la temática del mar y la libertad. En la "Pequeña ola" el tema central es la búsqueda de identidad de una olita perdida en el mar. Esa ola es la representación de la 
dicotomía cultural puertorriqueña, del ser o no ser, del pertenecer o no pertenecer a ese otro Caribe, cuya historia los abraza y a la vez los distancia, por la situación colonial de Puerto Rico. Por eso, abre el cuento con, "Había una pequeña olita que vivía solita en el mar. Como no tenía la protección de otras olas, las algas marinas la cuidaban de vientos huracanados" (p. 1). Esa olita veía desde la distancia a otras olas similares a ella, a las cuales no se acercaba y de las cuales se sentía parte, “Un día, allá en la lejanía, muy adentro del Mar Caribe, la olita vio a un grupo de olas cuyo vaivén y ritmo caribeño se sentía en todas las islas del archipiélago antillano... tururú... quimbambá... las olas cantaban y bailaban" (p. 2). Hasta que un día las gaviotas al verla triste le dicen, "Te llevaremos con tus hermanas al mar de las Antillas". La historia termina con la olita feliz, "paseándose con sus hermanas por el Mar Caribe y las Antillas". La intención de la voz narrativa de este cuento es la de mostrarle a un niño que la unidad es parte esencial de la sobrevivencia humana, puesto que "En la literatura infantil cuanto más cerca del lector estén los personajes más se identifica con la psicología de los personajes y más le gusta a un niño el libro que está leyendo" (Romero, 2012, s.p.). Esta misma idea se emplea en el cuento "Pancholo" en donde el tema de la libertad perdida se convierte en el eje motor del relato, "De momento sintió una mano fría que lo aprisionaba... ¡Pobre de nuestro amigo! Esta vez no escaparía" (Hidalgo de Jesús, 2016, p. 6). En este cuento hay suspenso y acción. El receptor, en cierta medida, se convierte en el personaje y vive a través de Pancholo su felicidad y sufre con él la tristeza de ser sacado de su ambiente natural y trasladado a otro ambiente que no reconoce. Asimismo, el tema del cuento sirve para mostrarle la malicia a un niño y darle el mensaje de que no todas las personas son buenas.

En "La ceiba", por otra parte, la temática gira en torno a la destrucción del ambiente y cómo un árbol emblemático de la resistencia colonial en Puerto Rico, sobrevive a los siglos de aniquilación cultural a los que ha sido sometido la isla, "La ceiba resistió los embates de los huracanes, los leñadores y de los modernos constructores... Entonces pasó inevitable. La ceiba se convirtió en árbol centenario, cuya historia silbaron por siglos los pájaros del archipiélago antillano" (p. 12). La ceiba también es sinónimo de la resistencia lingüística a la imposición de un idioma extranjero, inglés y que, por eso a pesar de tanto asedio cultural y lingüístico, aún se sigue hablando español en la isla. Aunque el tema sea poco complicado para un niño, lo que el niño recordará de la historia es que la perseverancia humana no tiene límites, lo que en cierta medida lo acerca a los intereses de lectura que "forman parte de su edad" (Sandra, 2011, p. 1). 


\subsection{María Luisa Lazzaro, "Una mazorca soñadora" (Venezuela) y Ana María Guillén Lazzaro, "El gato y la Begonia ya ni se asustan ni asombran" (Venezuela).}

En la creación de los cuentos para niños tenemos que darnos a la tarea de buscar modos de mostrar las cosas como verdaderas a la vez que las conectamos con el tono infantil que desarrollaremos en el cuento. Asimismo, hay que enfocarse en metáforas y temas que cautiven la atención del niño receptor. Por eso, Guillen Lazzaro (1999) y Lazzaro (1997) se valen de elementos de la naturaleza para ubicar la temática de sus cuentos. Lázzaro (1997) en su cuento "Una mazorca soñadora" desde un principio utiliza la imagen de una mazorca soñadora que, "quiso cambiar su destino inevitable" (Lazzaro, 1997, p. 1), para aproximarse al tema de la maternidad y la sobreprotección y enseñanzas maternas al luchar por la libertad; y al igual que la señora mazorca, sus hijos también escapan al final del

Así poco a poco mientras va avanzando el cuento emerge la imagen de una madre protectora que solo se preocupa en hacer de sus hijos (los granitos de maíz) seres fuertes y autosuficientes. Para ello se crea una comunicación entre madre e hijos a la vez que los protege y va preparando para la vida poema de lo que sería su fatídico destino, "Saltaron tan pronto Comprendieron el destino Y corriendo, corriendo, llegaron a las estrellas. Se montaron en el sol. Se metieron en la luna" (p. 14). En este cuento la protagonista, mazorca venezolana, quiere cambiar su destino, a la vez que se afana en proteger a sus hijos de ese destino, puesto que, "Ser arepa, Chicha, Cachapa O bollos tiernos no quería" (p. 1-2). Así poco a poco mientras va avanzando el cuento emerge la imagen de una madre protectora que solo se preocupa en hacer de sus hijos (los granitos de maíz) seres fuertes y autosuficientes. Para ello se crea una comunicación entre madre e hijos a la vez que los protege y va preparando para la vida, "Mientras maduraba fue hablando con sus hijos granitos refulgentes de energía y vida" (p. 3). Del mismo modo, la mazorca se da en la misión de irlos educando en el desarrollo de sus cinco sentidos a la vez que les da un espacio de esparcimiento para su crecimiento intelectual y corporal, "Mazorca Madre entendiendo el alma de sus granitos amarillos fue aflojando la carne prisionera de sus niños" ( $p$. 12). Pero como la protección materna no dura toda una vida, lo cual es el mensaje del cuento, los granitos al verse amenazados de ser separados y cocinados, toman la determinación de huir de su posible fatal destino para ir en busca de uno más progresivo, " $\mathrm{Y}$ comenzaron a crecer Germinando maná Música celestial. Alimento de ángeles Ilegando hasta la galaxia más vital del universo" (p. 16). Digamos que, al liberar a sus personajes, Lazzaro logra reestablecer el balance entre la vida y la muerte y la lucha por la sobrevivencia humana. 
Ana María Guillén Lazzaro en "El gato y la begonia ya ni se asustan ni asombran", utiliza la relación entre una niña, su mascota y su planta para adentrase en el tema de las desavenencias entre un gato y una flor, al mismo tiempo que toca el tema del acoso (bullying) en la vida de los personajes. Fifí es un gato que le tiene rabia a una begonia, “... la quería arañar. Se la quedaba mirando y mirando como si quisiera almorzar" (Guillén Lazzaro, 1999, p. 1). Begonia es una mata que en las noches cuando nadie la ve se burla de Fifí y lo enreda entre sus hojas, "y lo mareaba y mareaba" (p. 8). Como el problema de quién acosa a quién no es tan claro, la autora utiliza un personaje neutro, la niña, para que se encargue de hablarle a la begonia de los miedos del gato y del porqué de su comportamiento, “¿Por qué en vez de perseguir a Fifí no juegas con él? ¿No ves que se asusta?" (p. 10). De este modo, se resuelve el asunto y los dos personajes enemigos terminan siendo amigos, "Desde ese día Fifí y la begonia juegan de día y duermen a la noche" (p. 11). En este cuento el niño se identifica de inmediato con la emisora, la niña, quien sirve de intermediaria entre la relación mutua de acoso entre ambos personajes, la begonia y el gato. Esto lleva a que se reitere el mensaje de aprender a enfrentarse y defenderse de un acosador. Del mismo modo, lleva al niño a entender que existen otros medios para hacer justicia y que la violencia no siempre será la respuesta a la injusticia. Finamente, el texto también da el mensaje de que puede existir una amistad entre dos enemigos si surge un diálogo entre ellos.

\section{La lucha por el ambiente en un viaje intergaláctico}

En esta parte analizamos la novela corta Aurora y sus viajes intergalácticos de María Juliana Villafañe (Puerto Rico). A diferencia de los otros textos estudiados, en esta novela corta los temas de género, cultura y ambiente son presentados dentro de una perspectiva extrasensorial y sideral vista a través de los ojos de una niña y su amistad con un príncipe de otra galaxia.

\subsection{Aurora y Sus Viajes intergalácticos de María Juliana Villafañe (Puerto Rico).}

Dentro de la literatura infantil también entra la temática de viajes intergalácticos y sus personajes. Se puede decir que es una literatura orientada más hacia un público infantil de mayor edad, dado que los textos son más extensos y cuentan con pocas imágenes por lo que es difícil para los más pequeños poder leerlos. Mas, sin embargo, para un preadolescente este tipo de texto se convierte en una lectura agradable y fascinante. Este es el caso de Aurora y sus viajes intergalácticos escrito por María Juliana Villafañe. El libro se puede considerar como un cuento largo o una novelita corta cuya temática engancha a cualquier niño lector, como ha dicho una niña puertorriqueña, “¿Qué es lo que tiene este cuento, que lo empiezas a leer y no lo puedes soltar?" (2003, octubre 22). En el cuento o novela corta la autora trata el tema de la imaginación humana, "Y así poco a poco, en sus escapadas con Milsy Aurora fue descubriendo otros mundos, 
otros seres, que, aunque diferentes, la llenaban de felicidad" (p. 3), a la vez que aboga por la preservación de la naturaleza mediante el reciclaje, que el amor no tiene fronteras espaciales y que tal vez, quién sabe, en otras galaxias existe una vida muy parecida a la del planeta Tierra. Es decir, como apunta Adriana Manzanares, "hay una reflexión acerca de la existencia humana, de la vida y de los sueños, de la felicidad que no es un estado infinito del ser, de la importancia de creer, de lo bueno que es ser agradecido" (s.n. 2018). Esa vida es explorada por Villafañe en la historia de Aurora y sus amigos a través de la personificación de una estrella y una latita oxidada.

Al principio de la novela, la autora le da características humanas a la estrella Milsy, quien se convierte en el ente que guía a Aurora hacia su encuentro con el príncipe Siul en otra galaxia. Es decir, estamos ante la inversión de la historia cristiana del nacimiento de Jesús y la estrella de oriente. Por eso, la historia se vuelve en la búsqueda del amor eterno y el dolor por el que tiene que atravesar la protagonista para conseguirlo, "Se negaba a ver a sus amigos, no quería hablar ni con Milsy, la estrella luminosa, con la que recorría el mundo, ni con Kixt, su amigo intergaláctico de otra especie que fue el intermediario entre ella y el príncipe para la cita inigualable" (Villafañe 2018, p. 5). Del mismo modo, Milsy se convierte en el motor de la comunicación humana entre Aurora, sus amigos, el príncipe y los otros personajes intergalácticos que lo rodean.

La historia de Aurora y su compenetración con Mitsy se profundiza en el cuento al entrar en la narración el tema de la destrucción del ambiente con la personificación de una latita oxidada, llamada Morena que se convierte en su alter ego. Ella es quien de ahora en adelante medirá el pasar del tiempo en los viajes intergalácticos de la protagonista. La acompañará a todas partes dirigiéndole los pasos en la tierra y en sus aventuras intergalácticas. También será su consuelo en momentos de tristeza y soledad y será la que ayuda a Aurora a completar el ciclo desdoblamiento humano entre el planeta y otras galaxias.

\section{Conclusión}

Mirar hacia la visión del entendimiento de la vida de un niño o un preadolescente no es tarea fácil para ningún autor que se dedique a escribir este tipo de literatura. Se requiere paciencia, observación y mucha imaginación para lograr el cometido, y a un buen ilustrador que logre captar el sentido de la palabra en una ilustración colorida y detallada. Los textos aquí descritos y brevemente analizados son fuentes literarias latinoamericanas, que si bien no conocidas, logran captar la atención de un lector niño o preadolescente al mismo tiempo que son cuentos y poemas ambientalistas en los que los discursos de género y solidaridad humana están muy presentes. Por ejemplo, los poemas de Bella Clara Ventura trascienden la idea de la mujer sumisa 
judeo-cristiana vista a través del crisol de distintas voces narrativas que rompen con los discursos tradicionales bíblicos del viejo testamento. "Are y Pita" y "La olita" de Amarilis Hidalgo de Jesús, por otra parte, simbolizan enclaves culturales que se rebelan al exilio, asimilación y aislamiento cultural. A esta temática se añade la del acoso de género expuesto en "El gato y la begonia ya ni se asustan ni asombran" de Ana María Guillén Lazzaro. No muy distante al tema de las disputas familiares, está el tema de la desestructuración familiar desarrollado por María Luisa Lazzaro en "Una mazorca soñadora" y la lucha de una madre para mantener la unidad familiar protegiendo a los hijos de la maldad humana. Un tema muy parecido dentro de un contexto ambientalista, lo presenta Amarilis Hidalgo de Jesús en "Pancholo, el isleño" y "La ceiba" en donde el tema del desarraigo humano y la lucha por la existencia se combinan con la temática ambientalista tan presente en la historia contemporánea de las islas del Caribe. Dicha temática la retoma María Juliana Villanueva en Aurora y sus viajes intergalácticos a través de la historia de una niña y su lucha por mejorar el ambiente para proteger al planeta y su isla. Asimismo, en los textos estudiados se exploran temáticas parecidas dentro de un contexto cultural universal a través de la experiencia vivida por cada uno de los personajes o voces poéticas. De igual modo, existe una conexión literaria y cultural en estos textos que gira en torno al desarrollo de una temática similar latinoamericana con elementos lingüísticos que, si bien son distintos en cada nación, también son parte del conglomerado cultural latinoamericano. Cada texto

Cada texto representa la realidad cultural y social que viven las naciones latinoamericanas a través de conflictos políticos, de género, cultura y religión. Sin lugar a dudas, este conglomerado de temas es importante al aproximarse al estudio de la producción literaria de literatura infantil en las sociedades latinoamericanas, en donde la fauna y la imaginación humana se hacen eco de los problemas sociales, políticos y ecológicos que viven estas naciones representa la realidad cultural y social que viven las naciones latinoamericanas a través de conflictos políticos, de género, cultura y religión. Sin lugar a dudas, este conglomerado de temas es importante al aproximarse al estudio de la producción literaria de literatura infantil en las sociedades latinoamericanas, en donde la fauna y la imaginación humana se hacen eco de los problemas sociales, políticos y ecológicos que viven estas naciones. Por tanto, al adentrarse en su estudio un investigador, por fuerza tiene que conocer la historia e idiosincrasia del pueblo latinoamericano para poder entender la producción literaria infantil de las naciones latinoamericanas. 


\section{Referencias}

Bajour, C. (2013.). Nadar en aguas inquietas: Una aproximación a la poesía infantil de hoy. Imaginaria. Revista quincenal sobre literatura infantil y juvenil, (332). Recuperado de https://imaginaria.com.ar/2013/09/nadar-en-aguas-inquietas-una-aproximacion-a-la-poesiainfantil-de-hoy/

Botelho, M. J., \& Rudman, M. K. (2009). Critical Multicultural Analysis of Children's Literature: Mirrors, Windows, and Doors. United Kingdom: Routledge

Sandra (2011, Marzo 22). ¿Cómo Analizar Un Libro De Literatura Infantil? (Prueba I) [Entrada blog], Recuperado de https://sandra-colorincolorado.blogspot.com/2011/03/como-analizar-un-librode-literatura.html

Cruz Vázquez, A. (2018, febrero 18). Entrevista con Yesenia Rosado Vázquez Hidalgo. [Messenger Facebook].

Garralón, A. (n.d.). La crítica es bella. Cómo analizar los libros para niños. Recuperado de http://www.cervantesvirtual.com/obra-visor/la-crtica-es-bella-cmo-analizar-los-libros-paranios-0/html/fff76254-82b1-11df-acc7-002185ce6064_2.html

Guillén Lazzaro, A. M. (1999). El gato y la begonia ya ni asustan ni asombran. Mérida, Venezuela: Escarcha azul.

Hidalgo de Jesús, A. (2016). Cuentos de Isla y mar. Lima: Alejo Ediciones.

Lalas, J. (2007). Teaching for Social Justice in Multicultural Urban Schools: Conceptualization and Classroom Implication. Multicultural Education, 19(1), 17-21.

Lazzaro, M. L. (1997). Una mazorca soñadora. Mérida, Venezuela: La Escarcha Azul.

Malcolm, Z., \& Lowery, R. M. (2011). Reflections of the Caribbean in Children's Picture Books: A Critical Multicultural Analysis. Multicultural Education, 14(3), 46-50.

Manzanares, A. (2003, diciembre 18). Radio Programas del Perú. de María Juliana Villafañe website:https://www.mariajuliana.com/resenas/aurora-y-sus-viajes-intergalacticos-pormaria-juliana-villafane/

Romero, A. (2012). Bloque I: Literatura Infantil, Análisis y Selección de Literatura, [Entrada blog ] Recuperado de http://litelartedelapalabra.blogspot.com/2012/01/bloque-i-literatura-infantilanalisis-y.html

Reseñas del libro Aurora y Sus Viajes Intergalácticos. [Entrada blog], María Juliana Villafañe website: Recuperado de https://www.mariajuliana.com/resenas/aurora-y-sus-viajes-intergalacticospor-maria-julinana-villafane/

Ventura, B. C. (2001). Hechizos de bosque. Bogotá: Club Editor.

Villafañe, M. J. (2018). Aurora y Sus Viajes Intergalácticos (3ª ed.). México: Julianadas Inc.

\section{How to cite this paper:}

Hidalgo de Jesus, A. (2020). De bosque, sueños, galaxias y mares: cuentos, poemas y narrativa para niños y adolescentes. Journal of Literary Education, (3), pp. 80-92. doi: 10.7203/JLE.3.17012 